Research Paper

\title{
Clinical predictors of prognosis in patients with traumatic brain injury combined with extracranial trauma
}

\author{
Chengli Liu*, Jie Xie*, Xinshuang Xiao, Tianyu Li, Hui Li, Xiangjun Bai, Zhanfei $\mathrm{Li}^{\bowtie}$ and Wei Wang ${ }^{\bowtie}$ \\ Department of Traumatic Surgery, Tongji Hospital, Tongji Medical College, Huazhong University of Science and Technology, Wuhan 430030, P.R. China. \\ *These authors contributed equally to this manuscript. \\ $\triangle$ Corresponding authors: Wei Wang, MD, PhD, Department of Traumatic Surgery, Tongji Hospital, Tongji Medical College, Huazhong University of Science and \\ Technology, Wuhan 430030, P.R. China. E-mail: wangwei@tjh.tjmu.edu.cn; Zhanfei Li, MD, PhD, Department of Traumatic Surgery, Tongji Hospital, Tongji Medical College, \\ Huazhong University of Science and Technology, Wuhan 430030, P.R. China. E-mail: lezhfei@163.com. \\ (C) The author(s). This is an open access article distributed under the terms of the Creative Commons Attribution License (https://creativecommons.org/licenses/by/4.0/). \\ See http:/ /ivyspring.com/terms for full terms and conditions.
}

Received: 2020.10.23; Accepted: 2021.01.04; Published: 2021.02.05

\begin{abstract}
Objective: The purpose of this study was to investigate whether routine blood tests on admission and clinical characteristics can predict prognosis in patients with traumatic brain injury (TBI) combined with extracranial trauma.

Methods: Clinical data of 182 patients with TBI combined with extracranial trauma from April 2018 to December 2019 were retrospectively collected and analyzed. Based on GOSE score one month after discharge, the patients were divided into a favorable group (GOSE 1-4) and unfavorable group (GOSE 5-8). Routine blood tests on admission and clinical characteristics were recorded.

Results: Overall, there were 48 (26.4\%) patients with unfavorable outcome and 134 (73.6\%) patients with favorable outcome. Based on multivariate analysis, independent risk factors associated with unfavorable outcome were age (odds ratio [OR], 1.070; 95\% confidence interval [Cl], 1.018-1.124; $p<0.01$ ), admission Glasgow Coma Scale (GCS) score (OR, 0.807; 95\% Cl, 0.675-0.965; $p<0.05$ ), heart rate (OR, 1.035; 95\% Cl, 1.004-1.067; $p<0.05)$, platelets count (OR, 0.982; 95\% Cl, 0.967-0.997; $p<0.05)$, and tracheotomy (OR, 15.201; 95\% Cl, 4.121-56.078; $p<0.001)$. Areas under the curve (AUC) of age, admission GCS, heart rate, tracheotomy, and platelets count were $0.678(95 \% \mathrm{Cl}, 0.584-0.771), 0.799$ (95\% Cl, 0.723-0.875), $0.652(95 \% \mathrm{Cl}, 0.553-0.751), 0.776(95 \% \mathrm{Cl}, 0.692-0.859)$, and $0.688(95 \% \mathrm{Cl}$, 0.606-0.770), respectively.

Conclusions: Age, admission GCS score, heart rate, tracheotomy, and platelets count can be recognized as independent predictors of clinical prognosis in patients with severe TBI combined with extracranial trauma.
\end{abstract}

Key words: prognosis; traumatic brain injury; multiple trauma; prognostic factor

\section{Introduction}

Traumatic brain injury (TBI) is the leading cause of mortality, long-term disability, and cognitive impairment that particularly affects young people worldwide $[1,2]$. Prognosis of patients with traumatic brain injury is still unclear, and multiple studies have tried to identify predictors of outcome in these patients. Some studies in TBI patients have shown that old age, low admission Glasgow Coma Scale (GCS) score, high head abbreviated injury scale (AIS) score, poor pupillary reflex, hypoxia, increased intracranial pressure and tracheotomy were related with poor functional outcome [3-7]. In addition, high white blood cells, high neutrophil lymphocyte ratio (NLR), anemia, high blood glucose, high sodium, and high uric acid in routine blood test were closely related to poor prognosis of neurological function [8-12]. Concentration of certain blood biomarkers, including S100B, glial fibrillary acidic protein (GFAP), tau, neuron-specific enolase (NSE), periostin, translocator protein, interleukin (IL)-8/33 and TWEAK, have also been reported as predictors of the final outcome [13-20].

Multiple trauma was defined as the injury associated with more than one body cavity or organ, 
which was considered to be the major cause of death and morbidity [21]. As showed in previous clinical studies, TBI was often accompanied by injuries of extracranial sites [22]. In patients with multiple trauma, prognostic factors included age, sex, ISS score, GCS score, injury mechanism, and systolic blood pressure [23-25]. Condition of TBI patients with multiple injuries involves multiple parts, which are often severe and difficult to diagnose and treat, and may influence their prognosis. Hypotension and coagulopathy resulting from an extracranial injury were important factors for secondary injury to TBI [26]. The above predictive factors should be evaluated thoroughly in patients with TBI and extracranial trauma.

Therefore, to study the influence of extracranial trauma on the prognosis of TBI, we analyzed patients with TBI combined with extracranial trauma and evaluated whether blood analysis at the admission and clinical characteristics can be used to predict the patients' prognosis.

\section{Material and methods}

This retrospective study included patients with traumatic brain injury combined with extracranial trauma who were admitted to our department between April 2018 and December 2019 in Tongji Hospital. The study was approved by the local Ethics Committee. The diagnosis was based on a history of injury, clinical manifestations, and radiological examination. The inclusion criteria were as follows: (1) traumatic brain injury with head AIS $\geq 3$, (2) at least one other body region with AIS $\geq 2$, (3) admission Injury Severity Score (ISS) $>15$, (4) interval from injury to hospital admission $<24 \mathrm{~h}$, and (5) age $\geq$ 18 years. Patients with missing or incomplete data and isolated TBI were excluded.

Data regarding age, gender, injury mechanism, time interval from injury to admission, blood pressure, heart rate, pupil size, pupillary reflex, admission GCS score, ISS score, head AIS score, injury position, use of tracheal intubation and tracheotomy, and complications during hospitalization were collected from electronic medical records in Tongji Hospital. Patients were followed up and evaluated for Glasgow Outcome Scale-extended (GOSE) score 1 month after discharge.

Patients with TBI were diagnosed using head computed tomography (CT) at admission. Acute brain injuries assessed by $\mathrm{CT}$ imaging included the following: epidural hematoma (EDH), subdural hematoma $(\mathrm{SDH})$, subarachnoid hemorrhage $(\mathrm{SAH})$, cerebral hemorrhage, and skull fracture. The head abbreviated injury score (AIS) was an internationally recognized traumatic injury scoring system, including codes in 9 different regions: head, face, neck, thorax, abdomen, spine, upper extremity, lower extremity, whole body, and other [27]. AIS was assessed as follows: minor ( 1 point), moderate ( 2 points), severe, not life-threatening (3 points), severe, life-threatening (4 points), critical (5 points), and lethal (6 points) [27-29]. Thereby, AIS $\geq 3$ was recognized as a severe TBI. The ISS score was calculated based on the severity of the highest AIS in up to three anatomic areas. ISS $>15$ was used to define severe multiple trauma because it may predict $10 \%$ mortality rate of trauma patients [30]. The GCS scores were classified as mild (13-15 points), moderate (9-12 points), and severe (3-8 points). The GOSE scores were dichotomized to two groups: favorable (good recovery to moderate disability; GOSE 5-8) and unfavorable (severe disability to death; GOSE 1-4) [31].

\section{Statistical analysis}

Continuous data were expressed as mean \pm standard deviation (SD), and compared using Student's $t$ test. Categorical variables were analyzed by Pearson Chi-square or Fisher's exact probability test. To identify predictors independently associated with the prognosis, we performed multivariate logistic regression analysis with variables that had shown a statistical trend $(p<0.1)$ in univariate analysis. The corresponding $95 \%$ confidence interval (95\% CI) was used to calculate and represent the odds ratio (ORs). The receiver operating characteristic (ROC) curve was used to show sensitivity and specificity of independent predictors to calculate the optimal cutoff points. The area under the ROC curve (AUC) was also calculated to judge the existence of discriminative ability. AUC $>0.5$ indicated discriminative ability, $\mathrm{AUC}=1$ indicated complete discriminative ability, while AUC $<0.5$ indicated no discriminative ability. All tests were two-sided, and $p$ $<0.05$ was considered statistically significant. Statistical analysis was conducted using SPSS 22.0.

\section{Results}

In total, 534 patients with traumatic brain injury were collected and assessed in this study. Among 182 patients finally included in the present study, unfavorable and favorable groups comprised 48 $(26.4 \%)$ and $134(73.6 \%)$ patients, respectively. Age distribution of the patients is shown in Figure 1. The mean age was $50.41 \pm 14.42$ years (range 18 -84 years). There were $27(14.8 \%)$ older patients (>64 years) with $15(11.2 \%)$ patients in favorable groups and $12(25.0 \%)$ in unfavorable groups, which were statistically different. 


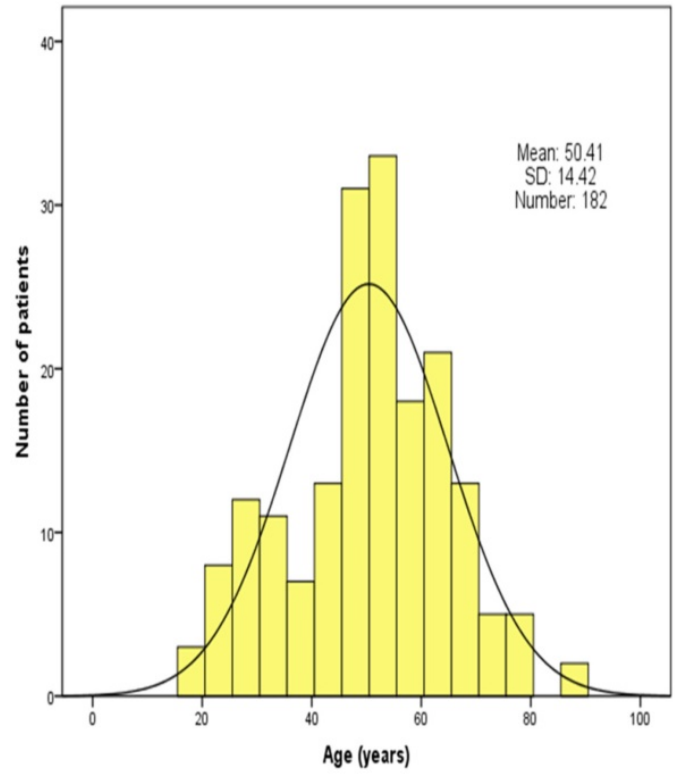

Figure 1. Age distribution of patients in the study population.

Table 1. Clinical characteristics of patients in univariate analysis

\begin{tabular}{|c|c|c|c|c|}
\hline Characteristic & $\begin{array}{l}\text { Total } \\
(\mathrm{N}=182)\end{array}$ & $\begin{array}{l}\text { Favorable } \\
\text { outcome } \\
(\mathrm{N}=134)\end{array}$ & $\begin{array}{l}\text { Unfavorable } \\
\text { outcome } \\
(\mathrm{N}=48)\end{array}$ & $p$ value \\
\hline Age (years), mean (SD) & $50.41 \pm 14.42$ & $48.40 \pm 13.42$ & $56.04 \pm 15.71$ & $<0.01$ \\
\hline Old men $(\geq 65), n(\%)$ & $27(14.8 \%)$ & $15(11.2 \%)$ & $12(25.0 \%)$ & $<0.05$ \\
\hline Sex (men), n (\%) & $135(74.2 \%)$ & $99(73.9 \%)$ & $36(75.0 \%)$ & 0.879 \\
\hline $\begin{array}{l}\text { Interval time (hours), } \\
\text { mean (SD) }\end{array}$ & $10.17 \pm 5.77$ & $10.29 \pm 5.76$ & $9.83 \pm 5.84$ & 0.641 \\
\hline \multicolumn{5}{|l|}{ Injury mechanisms, n (\%) } \\
\hline Traffic accident & $118(64.8 \%)$ & $83(61.9 \%)$ & $35(72.9 \%)$ & 0.367 \\
\hline Falls & $43(23.6 \%)$ & $35(26.9 \%)$ & $7(14.6 \%)$ & \\
\hline Assaults & $5(2.7 \%)$ & $4(3.0 \%)$ & $1(2.1 \%)$ & \\
\hline Others/unknown & $16(8.8 \%)$ & $11(8.2 \%)$ & $5(10.4 \%)$ & \\
\hline Admission GCS score & $11.68 \pm 3.98$ & $12.87 \pm 3.11$ & $8.35 \pm 4.26$ & $<0.001$ \\
\hline GCS score $\leq 8, \mathrm{n}(\%)$ & $48(26.4 \%)$ & $20(14.9 \%)$ & $28(58.3 \%)$ & $<0.001$ \\
\hline \multicolumn{5}{|l|}{ Pupil size, n (\%) } \\
\hline $\begin{array}{l}\text { Diameter of both pupils } \\
\geq 4 \mathrm{~mm}\end{array}$ & $7(3.8 \%)$ & $1(0.7 \%)$ & $6(12.5 \%)$ & $<0.001$ \\
\hline $\begin{array}{l}\text { Diameter of one pupil } \\
\geq 4 \mathrm{~mm}\end{array}$ & $13(7.1 \%)$ & $6(4.5 \%)$ & $7(14.6 \%)$ & \\
\hline $\begin{array}{l}\text { Diameter of both pupils } \\
<4 \mathrm{~mm}\end{array}$ & $162(89.0 \%)$ & $127(94.8 \%)$ & $35(72.9 \%)$ & \\
\hline \multicolumn{5}{|l|}{ Pupillary reflex, n (\%) } \\
\hline Brisk & $135(74.2 \%)$ & $110(82.1 \%)$ & $25(52.1 \%)$ & $<0.001$ \\
\hline Sluggish & $24(13.2 \%)$ & $15(11.2 \%)$ & $9(18.8 \%)$ & \\
\hline Non-reactive & $23(12.6 \%)$ & $9(6.7 \%)$ & $14(29.2 \%)$ & \\
\hline $\begin{array}{l}\text { Systolic pressure }(\mathrm{mm} \mathrm{Hg}) \\
\text { mean }(\mathrm{SD})\end{array}$ & $124.28 \pm 19.69$ & $124.11 \pm 16.31$ & $124.75 \pm 27.22$ & 0.879 \\
\hline Heart rate, mean (SD) & $89.04 \pm 32.43$ & $83.83 \pm 14.11$ & $102.60 \pm 56.51$ & $<0.05$ \\
\hline $\begin{array}{l}\text { High heart rate }(>100 / \mathrm{min}) \text {, } \\
\mathrm{n}(\%)\end{array}$ & $40(22 \%)$ & $20(14.9 \%)$ & $20(41.7 \%)$ & $<0.001$ \\
\hline ISS score, mean (SD) & $26.17 \pm 7.45$ & $25.07 \pm 6.69$ & $29.23 \pm 8.62$ & $<0.01$ \\
\hline ISS score $>25, \mathrm{n}(\%)$ & $81(44.5 \%)$ & $52(38.8 \%)$ & $29(60.4 \%)$ & $<0.05$ \\
\hline Head AIS score, mean (SD) & $3.63 \pm 0.67$ & $3.50 \pm 0.65$ & $4.00 \pm 0.62$ & $<0.001$ \\
\hline Chest injury, $\mathrm{n}(\%)$ & $140(76.9 \%)$ & $108(80.6 \%)$ & $32(66.7 \%)$ & $<0.05$ \\
\hline Abdominal injury, $\mathrm{n}(\%)$ & $64(35.2 \%)$ & $47(35.1 \%)$ & $17(35.4 \%)$ & 0.966 \\
\hline Pelvic injury, $\mathrm{n}(\%)$ & $27(14.8 \%)$ & $19(14.2 \%)$ & $8(16.7 \%)$ & 0.677 \\
\hline Limb injury, $\mathrm{n}(\%)$ & $79(43.4 \%)$ & $65(48.5 \%)$ & $14(29.2 \%)$ & $<0.05$ \\
\hline Epidural hematoma, n (\%) & $69(37.9 \%)$ & $52(38.8 \%)$ & $17(35.4 \%)$ & 0.678 \\
\hline Subdural hematoma, n (\%) & $111(61.0 \%)$ & $80(59.7 \%)$ & $31(64.6 \%)$ & 0.552 \\
\hline $\begin{array}{l}\text { Subarachnoid hemorrhage, } \\
\mathrm{n}(\%)\end{array}$ & $125(68.7 \%)$ & $87(64.9 \%)$ & $38(79.2 \%)$ & 0.068 \\
\hline Cerebral hemorrhage, n (\%) & $76(41.8 \%)$ & $51(38.1 \%)$ & $25(52.1 \%)$ & 0.091 \\
\hline Skull fracture, n (\%) & $109(59.9 \%)$ & $87(64.9 \%)$ & $22(45.8 \%)$ & 0.021 \\
\hline Craniotomy, n (\%) & $32(17.6 \%)$ & $15(11.2 \%)$ & $17(35.4 \%)$ & $<0.01$ \\
\hline Tracheal intubation, $\mathrm{n}(\%)$ & $60(33.0 \%)$ & $25(18.7 \%)$ & $35(72.9 \%)$ & $<0.001$ \\
\hline Tracheotomy, n (\%) & $55(30.2 \%)$ & $21(15.7 \%)$ & $34(70.8 \%)$ & $<0.001$ \\
\hline
\end{tabular}

\begin{tabular}{lllll}
\hline Characteristic & $\begin{array}{l}\text { Total } \\
(\mathrm{N}=182)\end{array}$ & $\begin{array}{l}\text { Favorable } \\
\text { outcome } \\
(\mathrm{N}=134)\end{array}$ & $\begin{array}{l}\text { Unfavorable } \\
\text { outcome } \\
(\mathrm{N}=48)\end{array}$ & $p$ value \\
\hline Pulmonary infection, $\mathrm{n}(\%)$ & $31(17.0 \%)$ & $15(11.2 \%)$ & $16(33.3 \%)$ & $<0.001$ \\
LEVT, $\mathrm{n}(\%)$ & $30(16.5 \%)$ & $25(18.7 \%)$ & $5(10.4 \%)$ & 0.187 \\
Death, $\mathrm{n}(\%)$ & $25(13.7 \%)$ & 0 & $25(52.1 \%)$ & $<0.001$ \\
\hline
\end{tabular}

GCS: Glasgow Coma Scale; ISS: Injury Severity Score; AIS: Abbreviated injury scale; LEVT: Lower extremity venous thrombosis.

There were $135(74.2 \%)$ men and 47 (25.8\%) women in the study population. The mean time interval from the head injury to admission was 10.17 \pm 5.77 hours. The injury was mainly caused by traffic accident $(118,64.8 \%)$, followed by falls (43, $23.6 \%)$, assaults $(5,2.7 \%)$, and others/unknown (16, $8.8 \%)$. The admission GCS score was $11.68 \pm 3.98$ and admission ISS score was $26.17 \pm 7.45$, in which the head AIS score was $3.63 \pm 0.67$. Overall, $140(76.9 \%)$ patients also had a chest injury, 64 (35.2\%) had abdominal injury, while pelvic injury and limb injury were recorded in $27(14.8 \%)$ and $79(43.4 \%)$ patients, respectively. Based on the results of CT imaging, all patients had an abnormal CT brain scan and there were $69(37.9 \%)$ patients with EDH, 111 (61.0\%) with SDH, 125 (68.7\%) with SAH, and 76 (41.8\%) with intracranial hemorrhage. Skull fracture was present in $109(59.9 \%)$ patients. A total of $32(17.6 \%)$ patients were subjected to craniotomy and decompressive craniectomy. $60(33 \%)$ and $55(30.2 \%)$ patients underwent tracheal intubation and tracheotomy, respectively. During hospitalization, 31 (17\%) patients developed pulmonary infection, and lower extremity venous thrombosis (LEVT) occurred in 30 (16.5\%) patients. Total mortality at 1 month after discharge was $25(13.7 \%)$. Baseline clinical characteristic of the two groups are displayed in Table 1.

White blood cell (WBC) count was $12.99 \pm 4.33$ $\left(\times 10^{9} / \mathrm{L}\right)$, among which neutrophils count was 11.43 $\pm 4.09\left(\times 10^{9} / \mathrm{L}\right)$ and lymphocytes count was $0.80 \pm$ $0.51\left(\times 10^{9} / \mathrm{L}\right)$. High WBC $\left(>10 \times 10^{9} / \mathrm{L}\right)$ was found in $138(75.8 \%)$ patients, high neutrophils percentage $(>75 \%)$ was recorded in $175(96.2 \%)$ patients, whereas low lymphocytes percentage $(<20 \%)$ was found in 178 $(97.8 \%)$ patients. The NLR was $17.85 \pm 10.44$. Hemoglobin level was $110.90 \pm 25.36(\mathrm{~g} / \mathrm{L})$. Platelets count was $154.99 \pm 53.83\left(\times 10^{9} / \mathrm{L}\right)$. Low platelets $(<$ $\left.120 \times 10^{9} / \mathrm{L}\right)$ and anemia $(<110 \mathrm{~g} / \mathrm{L})$ were found in 54 $(29.7 \%)$ and $74(40.7 \%)$ patients, respectively. Albumin was $35.43 \pm 7.14(\mathrm{~g} / \mathrm{L})$, and low albumin $(<35 \mathrm{~g} / \mathrm{L})$ was found in $78(42.9 \%)$ patients. Blood $\mathrm{Na}+$ concentration was $141.08 \pm 3.57(\mathrm{mmol} / \mathrm{L})$, and high $\mathrm{Na}+$ concentration (> $145 \mathrm{mmol} / \mathrm{L}$ ) was present in 22 $(12.1 \%)$ patients. Blood $\mathrm{K}+$ concentration was $4.21 \pm$ $0.53(\mathrm{mmol} / \mathrm{L})$, and low $\mathrm{K}+$ concentration $(<3.5$ $\mathrm{mmol} / \mathrm{L})$ was found in eight patients $(4.4 \%)$. Blood urea nitrogen $(\mathrm{BUN})$ was $5.82 \pm 2.73(\mathrm{mmol} / \mathrm{L})$, and high BUN (>8 mmol/L) was noted in $16(8.8 \%)$ 
patients. Blood creatinine was $78.96 \pm 68.26(\mu \mathrm{mol} / \mathrm{L})$, and high creatinine $(>110 \mu \mathrm{mol} / \mathrm{L})$ was recorded in $12(6.6 \%)$ patients. Blood uric acid (UA) was $300.12 \pm$ $100.48(\mu \mathrm{mol} / \mathrm{L})$, and high UA (> $417 \mu \mathrm{mol} / \mathrm{L})$ was present in $26(14.3 \%)$ patients. Blood glucose was 8.32 $\pm 2.78(\mathrm{mmol} / \mathrm{L})$, and hyperglycemia $(>8.0 \mathrm{mmol} / \mathrm{L})$ was verified in $87(47.8 \%)$ patients. For the overall results of coagulation tests, prothrombin time (PT) was $15.64 \pm 2.78$ (s), international normalized ratio (INR) was $1.60 \pm 4.59$, fibrinogen was $2.35 \pm 1.01$ $(\mathrm{g} / \mathrm{L})$, activated partial thromboplastin time (APTT) was $37.45 \pm 7.44$ (s), and thrombin time (TT) was 16.15 \pm 2.01 (s). High PT ( $\geq 15 \mathrm{~s})$ was found in 96 (52.7\%), high INR $(>1.2)$ in $79(43.4 \%)$, low fibrinogen $(<2$ $\mathrm{g} / \mathrm{L})$ in $65(35.7 \%)$, high APTT (> 45s) in $16(8.8 \%)$, and high TT $(>19 \mathrm{~s})$ in $13(7.1 \%)$ patients. Laboratory parameters are shown in Table 2.

Table 2. Routine laboratory parameters of the patients in univariate analysis

\begin{tabular}{|c|c|c|c|c|}
\hline Parameters & $\begin{array}{l}\text { Total } \\
(\mathrm{N}=182)\end{array}$ & $\begin{array}{l}\text { Favorable } \\
\text { outcome } \\
(\mathrm{N}=134)\end{array}$ & $\begin{array}{l}\text { Unfavorable } \\
\text { outcome } \\
(\mathrm{N}=48)\end{array}$ & $p$ value \\
\hline $\begin{array}{l}\text { WBC count }\left(\times 10^{9} / \mathrm{L}\right) \text {, } \\
\text { mean }(\mathrm{SD})\end{array}$ & $12.99 \pm 4.33$ & $12.71 \pm 4.27$ & $13.79 \pm 4.44$ & 0.14 \\
\hline High WBC count, n (\%) & $138(75.8 \%)$ & $100(74.6 \%)$ & $38(79.2 \%)$ & 0.528 \\
\hline $\begin{array}{l}\text { Neutrophils count }\left(\times 10^{9} / \mathrm{L}\right) \text {, } \\
\text { mean }(\mathrm{SD})\end{array}$ & $11.43 \pm 4.09$ & $11.17 \pm 4.10$ & $12.14 \pm 4.02$ & 0.16 \\
\hline $\begin{array}{l}\text { Neutrophils percentage (\%), } \\
\text { mean (SD) }\end{array}$ & $87.16 \pm 5.47$ & $86.95 \pm 5.65$ & $87.72 \pm 4.93$ & 0.402 \\
\hline $\begin{array}{l}\text { High neutrophils } \\
\text { percentage, } \mathrm{n}(\%)\end{array}$ & $175(96.2 \%)$ & $128(95.5 \%)$ & $47(97.9 \%)$ & 0.762 \\
\hline $\begin{array}{l}\text { Lymphocytes count } \\
\left(\times 10^{9} / \mathrm{L}\right) \text {, mean }(\mathrm{SD})\end{array}$ & $0.80 \pm 0.51$ & $0.81 \pm 0.53$ & $0.80 \pm 0.43$ & 0.887 \\
\hline $\begin{array}{l}\text { Lymphocytes percentage } \\
(\%) \text {, mean (SD) }\end{array}$ & $6.67 \pm 4.21$ & $6.84 \pm 4.31$ & $6.19 \pm 3.91$ & 0.357 \\
\hline $\begin{array}{l}\text { Low lymphocytes } \\
\text { percentage, } \mathrm{n}(\%)\end{array}$ & $178(97.8 \%)$ & $131(97.8 \%)$ & $47(97.9 \%)$ & 1.000 \\
\hline NLR, mean (SD) & $17.85 \pm 10.44$ & $17.57 \pm 10.73$ & $18.64 \pm 9.67$ & 0.544 \\
\hline $\begin{array}{l}\text { Platelets count }\left(\times 10^{9} / \mathrm{L}\right) \text {, } \\
\text { mean }(\mathrm{SD})\end{array}$ & $154.99 \pm 53.83$ & $164.10 \pm 54.97$ & $129.56 \pm 41.36$ & $<0.001$ \\
\hline Low platelets count, n (\%) & $54(29.7 \%)$ & $31(23.1 \%)$ & $23(47.9 \%)$ & $<0.01$ \\
\hline $\begin{array}{l}\text { Hemoglobin }(\mathrm{g} / \mathrm{L}) \text {, mean } \\
\text { (SD) }\end{array}$ & $110.90 \pm 25.36$ & $113.50 \pm 24.09$ & $103.65 \pm 27.58$ & $<0.05$ \\
\hline Anemia, n (\%) & $74(40.7 \%)$ & $47(35.1 \%)$ & $27(56.3 \%)$ & $<0.05$ \\
\hline Albumin $(\mathrm{g} / \mathrm{L})$, mean $(\mathrm{SD})$ & $35.43 \pm 7.14$ & $36.30 \pm 6.33$ & $32.99 \pm 8.66$ & $<0.05$ \\
\hline Low albumin, $\mathrm{n}(\%)$ & $78(42.9 \%)$ & $46(34.3 \%)$ & $32(66.7 \%)$ & $<0.001$ \\
\hline $\begin{array}{l}\text { Blood creatinine }(\mu \mathrm{mol} / \mathrm{L}) \text {, } \\
\text { mean }(\mathrm{SD})\end{array}$ & $78.96 \pm 68.26$ & $70.40 \pm 20.20$ & $102.85 \pm 126.48$ & 0.083 \\
\hline High creatinine, $\mathrm{n}(\%)$ & $12(6.6 \%)$ & $5(3.7 \%)$ & $7(14.6 \%)$ & $<0.01$ \\
\hline $\begin{array}{l}\text { Blood } \mathrm{Na}+(\mathrm{mmol} / \mathrm{L}) \text {, } \\
\text { mean }(\mathrm{SD})\end{array}$ & $141.08 \pm 3.57$ & $140.63 \pm 3.21$ & $142.34 \pm 4.19$ & $<0.05$ \\
\hline $\begin{array}{l}\text { High Na+ concentration, } \\
\mathrm{n}(\%)\end{array}$ & $22(12.1 \%)$ & $10(7.5 \%)$ & $12(25.0 \%)$ & $<0.05$ \\
\hline $\begin{array}{l}\text { Blood } \mathrm{K}+(\mathrm{mmol} / \mathrm{L}) \\
\text { mean }(\mathrm{SD})\end{array}$ & $4.21 \pm 0.53$ & $4.17 \pm 0.47$ & $4.33 \pm 0.67$ & 0.088 \\
\hline Low $\mathrm{K}+$ concentration, $\mathrm{n}(\%)$ & $8(4.4 \%)$ & $6(4.5 \%)$ & $2(4.2 \%)$ & 0.928 \\
\hline $\begin{array}{l}\text { Blood BUN (mmol/L), } \\
\text { mean (SD) }\end{array}$ & $5.82 \pm 2.73$ & $5.50 \pm 1.78$ & $6.70 \pm 4.32$ & 0.069 \\
\hline High BUN, n (\%) & $16(8.8 \%)$ & $7(5.2 \%)$ & $9(18.8 \%)$ & $<0.01$ \\
\hline $\begin{array}{l}\text { Blood UA }(\mu \mathrm{mol} / \mathrm{L}) \text {, mean } \\
\text { (SD) }\end{array}$ & $\begin{array}{l}300.12 \pm \\
100.48\end{array}$ & $295.11 \pm 95.41$ & $314.09 \pm 113.37$ & 0.304 \\
\hline High UA, n (\%) & $26(14.3 \%)$ & $15(11.2 \%)$ & $11(22.9 \%)$ & $<0.05$ \\
\hline $\begin{array}{l}\text { Blood glucose (mmol/L), } \\
\text { mean (SD) }\end{array}$ & $8.32 \pm 2.78$ & $8.02 \pm 2.52$ & $9.14 \pm 3.28$ & $<0.05$ \\
\hline High glucose, n (\%) & $87(47.8 \%)$ & $57(42.5 \%)$ & $30(62.5 \%)$ & $<0.05$ \\
\hline $\mathrm{PT}(\mathrm{s})$, mean $(\mathrm{SD})$ & $15.64 \pm 2.78$ & $15.15 \pm 1.67$ & $16.98 \pm 4.40$ & $<0.01$ \\
\hline High PT, n (\%) & $96(52.7 \%)$ & $59(44.0 \%)$ & $37(77.1 \%)$ & $<0.001$ \\
\hline INR, mean (SD) & $1.60 \pm 4.59$ & $1.67 \pm 5.34$ & $1.40 \pm 0.49$ & 0.733 \\
\hline
\end{tabular}

\begin{tabular}{lllll}
\hline Parameters & $\begin{array}{l}\text { Total } \\
(\mathrm{N}=182)\end{array}$ & $\begin{array}{l}\text { Favorable } \\
\text { outcome } \\
(\mathrm{N}=134)\end{array}$ & $\begin{array}{l}\text { Unfavorable } \\
\text { outcome } \\
(\mathrm{N}=48)\end{array}$ & $p$ value \\
\hline High INR, n (\%) & $79(43.4 \%)$ & $48(35.8 \%)$ & $31(64.6 \%)$ & $<0.01$ \\
Fibrinogen (g/L), mean (SD) & $2.35 \pm 1.01$ & $2.41 \pm 1.06$ & $2.17 \pm 0.87$ & 0.149 \\
Low fibrinogen, n (\%) & $65(35.7 \%)$ & $42(31.3 \%)$ & $23(47.9 \%)$ & $<0.05$ \\
APTT (s), mean (SD) & $37.45 \pm 7.44$ & $36.38 \pm 4.69$ & $40.41 \pm 11.77$ & $<0.05$ \\
High APTT, n (\%) & $16(8.8 \%)$ & $7(5.2 \%)$ & $9(18.8 \%)$ & $<0.01$ \\
TT (s), mean (SD) & $16.15 \pm 2.01$ & $15.92 \pm 1.52$ & $16.80 \pm 2.91$ & 0.051 \\
High TT, n (\%) & $13(7.1 \%)$ & $7(5.2 \%)$ & $6(12.5 \%)$ & 0.093 \\
\hline
\end{tabular}

WBC: White blood cells; NLR: Neutrophil lymphocyte ratio; BUN: Blood urea nitrogen; UA: Uric acid; PT: Prothrombin time; INR: International normalized ratio; APTT: Activated partial thromboplastin time; TT: Thrombin time.

Univariate analysis showed that patients with favorable and unfavorable outcomes significantly differed in age, proportion of old men, admission GCS score, pupil size, pupillary reflex, heart rate, admission ISS score, head AIS score, skull fracture, craniotomy, tracheal intubation, tracheotomy, pulmonary infection, mortality, hemoglobin, platelets count, albumin, blood $\mathrm{Na}+$, blood glucose level, PT, and APTT.

After adjusting for confound factors in the multivariate logistic model, age, admission GCS score, heart rate, tracheotomy, and platelets count were significant predictors of the 1-month outcome after discharge (Table 3).

Table 3. Clinical outcomes in the patient population in multivariate regression analysis

\begin{tabular}{lllll}
\hline Variable & OR & $95 \%$ CI & $\rho$ value & B \\
\hline Age & 1.070 & $1.018-1.124$ & $\mathbf{0 . 0 0 7}$ & 0.068 \\
Admission GCS score & 0.807 & $0.675-0.965$ & $\mathbf{0 . 0 1 9}$ & -0.215 \\
Pupil size & 0.224 & $0.049-1.023$ & 0.054 & -1.498 \\
Pupillary reflex & 0.595 & $0.185-1.915$ & 0.384 & -0.520 \\
Heart rate & 1.035 & $1.004-1.067$ & $\mathbf{0 . 0 2 8}$ & 0.034 \\
Admission ISS score & 0.970 & $0.888-1.060$ & 0.504 & -0.030 \\
Head AIS score & 1.326 & $0.497-3.539$ & 0.573 & 0.282 \\
Craniotomy & 1.441 & $0.381-5.447$ & 0.590 & 0.365 \\
Tracheal intubation & 0.923 & $0.241-3.538$ & 0.907 & -0.080 \\
Tracheotomy & 15.201 & $4.121-56.078$ & $\mathbf{0 . 0 0 0}$ & 2.721 \\
Platelets count & 0.982 & $0.967-0.997$ & $\mathbf{0 . 0 2 2}$ & -0.018 \\
Hemoglobin & 0.987 & $0.958-1.016$ & 0.367 & -0.014 \\
Blood albumin & 1.137 & $0.990-1.304$ & 0.068 & 0.128 \\
Blood creatinine & 1.012 & $0.993-1.031$ & 0.218 & 0.012 \\
Blood Na+ concentration & 0.960 & $0.801-1.152$ & 0.664 & -0.040 \\
Blood K+ concentration & 0.718 & $0.234-2.201$ & 0.562 & -0.331 \\
Blood BUN & 0.775 & $0.553-1.086$ & 0.139 & -0.255 \\
Blood glucose & 0.959 & $0.775-1.188$ & 0.705 & -0.041 \\
PT & 1.060 & $0.644-1.745$ & 0.819 & 0.058 \\
APTT & 0.996 & $0.871-1.139$ & 0.956 & -0.004 \\
TT & 0.994 & $0.649-1.520$ & 0.976 & -0.006 \\
\hline
\end{tabular}

GCS: Glasgow Coma Scale; ISS: Injury Severity Score; AIS: Abbreviated injury scale; BUN: Blood urea nitrogen; PT: Prothrombin time; APTT: Activated partial thromboplastin time; TT: Thrombin time.

The results indicated that among continuous variables, age (OR, 1.070; 95\% confidence interval [CI], 1.018-1.124; $p<0.01)$, admission GCS score (OR, $0.807 ; 95 \% \mathrm{CI}, 0.675-0.965 ; p<0.05)$, heart rate (OR, $1.035 ; 95 \% \mathrm{CI}, 1.004-1.067 ; p<0.05)$, and platelets count 
(OR, 0.982; 95\% CI, 0.967-0.997; $p<0.05)$ were independently associated with the unfavorable outcome at 1 month after discharge. The results also showed that among categorical variables tracheotomy (OR, 15.201; 95\% CI, 4.121-56.078; $p<0.001$ ) was independently related with the unfavorable outcome at 1 month after discharge.

The ROC curve was used to express sensitivity and specificity of age, admission GCS score, heart rate, tracheotomy, and platelets count for predicting the prognosis (Figure 2). The results showed that the area under curve (AUC) of age, admission GCS, heart rate, tracheotomy, and platelets count was 0.678 (95\% CI, 0.584-0.771), 0.799 (95\% CI, 0.723-0.875), 0.652 (95\% CI, 0.553-0.751), 0.776 (95\% CI, 0.692-0.859), and 0.688 (95\% CI, 0.606-0.770), respectively (Table 4).

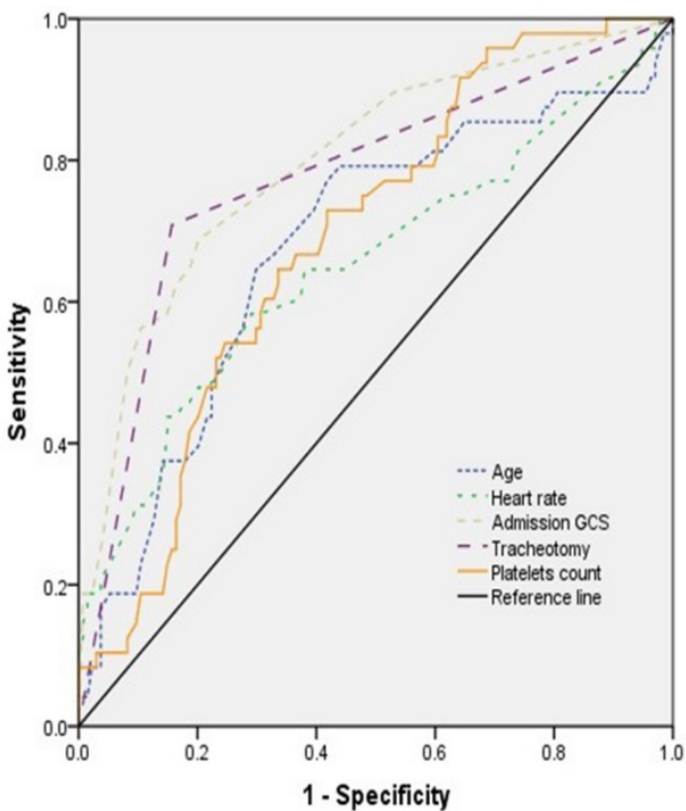

Figure 2. The ROC curve of different variables predicting the prognosis of patients with TBI combined with extracranial trauma.

Table 4. Results of work characteristic of AUC with different variables predicting prognosis one month after discharge

\begin{tabular}{lllllll}
\hline Variable & $\begin{array}{l}\text { Youden } \\
\text { index }\end{array}$ & Sensitivity & Specificity & AUC & $95 \%$ CI & $p$ value \\
\hline Age & 0.353 & 0.771 & 0.582 & 0.678 & $0.584-0.771$ & $<0.001$ \\
$\begin{array}{l}\text { Admission } \\
\text { GCS }\end{array}$ & 0.486 & 0.688 & 0.798 & 0.799 & $0.723-0.875$ & $<0.001$ \\
Heart rate & 0.292 & 0.583 & 0.709 & 0.652 & $0.553-0.751$ & $<0.05$ \\
Tracheotomy & 0.552 & 0.708 & 0.843 & 0.776 & $0.692-0.859$ & $<0.001$ \\
$\begin{array}{l}\text { Platelets } \\
\text { count }\end{array}$ & 0.311 & 0.729 & 0.582 & 0.688 & $0.606-0.770$ & $<0.001$ \\
\hline
\end{tabular}

GCS: Glasgow Coma Scale; AUC: Area Under Curve.

The prognostic model was established by using ROC for multi-factor diagnosis analysis. Model 1 included age, GCS, heart rate, and platelets count; model 2 included age, GCS, heart rate, platelets count, and tracheotomy (Figure 3). The AUC of the model 1 was 0.851 (0.792-0.909) with $91.7 \%$ sensitivity and $61.9 \%$ specificity. The AUC of the model 2 was 0.903 (0.857-0.949) with $91.7 \%$ sensitivity and $83.5 \%$ specificity (Table 5).

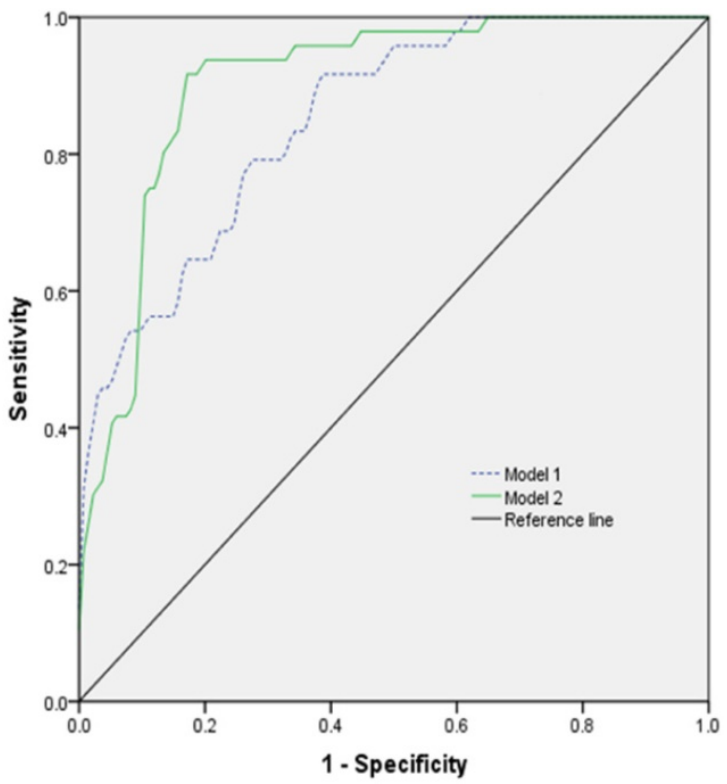

Figure 3. The ROC curve of different models predicting the prognosis of patients with $\mathrm{TBI}$ combined with extracranial trauma.

Table 5. Results of work characteristic of AUC with different models predicting prognosis one month after discharge

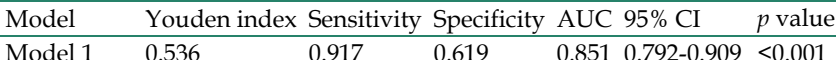

$\begin{array}{lllllll}\text { Model } 2 & 0.752 & 0.917 & 0.835 & 0.903 & 0.857-0.949<0.001\end{array}$

Model 1: Age + GCS + Heart rate + Platelets count; Model 2: Age + GCS + Heart rate + Platelets count + Tracheotomy. AUC: Area Under Curve.

\section{Discussion}

This study showed the predictive value of blood routine tests at admission and clinical characteristics for neurological functional outcome in patients with TBI combined with extracranial trauma at one month after discharge in level I trauma center. The purpose of this study was to analyze the clinical characteristics and routine blood test results that may predict the prognosis in patients with TBI combined with extracranial trauma. Moreover, although some blood parameters were predictive in univariate analysis, they did not remain significant after multivariate correction. Therefore, our study focused on the possibility to use blood values at admission and clinical characteristics as prognostic markers in patients with TBI combined with extracranial trauma.

In terms of clinical characteristics, our logistic regression model showed that for each additional year and point of age and heart rate, the risk of unfavorable prognosis increased by $7 \%$ and $3.5 \%$, respectively. For each point reduction in initial GCS and platelets at admission within 24 hours after 
injury, the risk of unfavorable outcome increased by $19.3 \%$ and $1.8 \%$, respectively. In addition, anyone undergoing tracheotomy had 15.201-fold higher risk for poor prognosis. The AUC of age, admission GCS score, heart rate, tracheotomy, and platelets count was $0.678,0.799,0.652,0.776$, and 0.688 , respectively.

Our study indicated a significant correlation between age and outcome at 1-month after discharge in patients with TBI and extracranial trauma. The age distribution histogram revealed that the age of patients was mainly between 40 and 70 years. In the unfavorable group, there were $25 \%$ of individuals with older age compared with $11.2 \%$ in the favorable group. Older age has been linked to worse outcomes, although possible reasons are still under discussion $[32,33]$. Among TBI patients, older patients more commonly use anticoagulants and antiplatelet agents $[34,35]$. Older individuals are more likely to experience domestic falls, which is associated with worse outcome compared with young individuals [1]. Moreover, we found that admission GCS score was an independent predictor of prognosis in TBI patients with extracranial trauma, which is consistent with some previous studies in TBI patients $[3,7,36]$. We did not confirm the ability of ISS to predict the prognosis of TBI patients after correcting for multiple blood indicators in a multivariate logistic regression model. However, our study confirmed that age and admission GCS can be used as remarkable predictors of the prognosis in TBI patients with extracranial trauma.

Heart rate is a vital sign and could be influenced by some pathological states, such as pain, shock, and intracranial hypertension. Reverse shock index, systolic blood pressure lower than the heart rate, also indicated an unfavorable outcome in patients with severe isolated TBI [37]. Moreover, another study revealed that cardio-cerebral network imbalance might influence the relationship of mean arterial pressure, intracranial pressure, and heart rate in sTBI patients [38]. As our study showed, heart rate was also an independent factor predicting the outcome in our patient population.

Tracheotomy is a common clinical procedure in patients with sTBI, which provides a stable and tolerated airway to ensure oxygen supply, despite some complications that may accompany the procedure [39]. Here we found that tracheotomy was an independent factor for unfavorable outcome. Some studies have shown increased survival in patients with tracheostomy compared with patients who remained intubated after severe TBI [40, 41]. However, the optimal time to perform tracheostomy remains a highly controversial topic. Early tracheostomy within 72 hours of admission reduced the duration of mechanical ventilation and length of stay in intensive care unit (ICU) in 120 patients with TBI [42]. A randomized trial and a retrospective meta-analysis indicated that early tracheostomy increased risk for hospital death and did not decrease ventilator-associated pneumonia rates [39, 43]. In contrast, several studies reported that early tracheostomy could improve prognosis in TBI patients [4].

The majority of patients had normal platelet count, and $29.7 \%$ of patients had low platelets in this study. We found that the platelets count was the only significant blood parameter in multivariate logistic regression model, apart from age, admission GCS score, and tracheotomy. Acute coagulopathy of trauma (ACT) is caused by tissue injury and tissue perfusion [44]. Coagulopathy is defined as low platelet count or elevated INR or prolonged APTT [45]. The platelet dysfunction, increased level of platelet distribution width (PDW), and low platelet count were associated with unfavorable outcome in TBI patients [46-49]. The fresh frozen plasma (FFP) resuscitation attenuated platelet dysfunction and improved survival in animals with multiple trauma [50]. Furthermore, the importance of ACT in TBI patients has been increasingly recognized. In a large population of patients with TBI, INR and APTT were recognized as independently related to in-hospital mortality $[7,51]$. High PT was also recognized as a predictor of mortality in patients with trauma $[49,52]$. However, PT, INR, and APTT were not independent predictors in this study.

Inflammation also plays an important role in TBI and multiple trauma [53, 54]. Mass release of proinflammatory factors caused by trauma stimulation or tissue necrosis can lead to leukocyte activation and lymphocytes deficiency [55-57]. Neutrophil activation has dual effects on TBI, which might contribute to repair mechanisms or aggravate the pathophysiology of trauma [58, 59]. The neutrophil-to-lymphocyte ratio (NLR) is associated with unfavorable outcomes in sTBI patients [8]. The majority of our patients had higher leukocyte and neutrophil counts and lower lymphocytes. The inflammatory stimulation caused by multiple injuries may cover the inflammatory manifestations caused by isolated traumatic brain injury, which may explain why inflammatory cell prediction was not significant.

Hypernatremia and hyperglycemia were associated with poor outcome after severe TBI [49, 60-64]. The main point is that stress response activates the hypothalamic-pituitary-adrenal axis and sympathetic nervous system, leading to elevated levels of neurohormones and insulin resistance [65]. Intensive insulin therapy was considered as a 
therapeutic strategy to treat cerebral metabolic distress in a previous study [66]. However, to prevent hypoglycemia, strict blood sugar control was not recommended [67]. Nevertheless, we did not find that high $\mathrm{Na}+$ concentration, hyperglycemia, and high BUN were independent predictors of outcomes in our study. In addition, prognosis of patients with TBI was worse in patients with anemia [49, 68,69]. Multiple trauma was also related with injury-associated anemia [70]. More than $50 \%$ of the patients in our study population had low hemoglobin levels. However, hemoglobin level was not an independent predictor of neurological prognosis in this study.

We applied the ROC curve and different combination models to evaluate the accuracy of some variables for predicting the outcome in patients with TBI combined with extracranial trauma. Our results showed that total combination models displayed proper accuracy to assess prognosis of patients, with $91.7 \%$ sensitivity and $83.5 \%$ specificity. The AUC of the model 2 was 0.903 and Youden index was 0.752 . The model 2 is useful for predicting the clinical outcome because these variables are easy to obtain. To predict the early prognosis of patients, we excluded tracheotomy as a variable and established the model 1. The AUC of the model 1 was 0.851 and Youden index was 0.536 , with $91.7 \%$ sensitivity and $61.9 \%$ specificity. The AUC of the model 2 was the largest, indicating the highest prognostic accuracy.

This study had several limitations. First, this was a single-center retrospective study, which is why selection bias may have existed. Second, this study investigated a relatively small cohort of patients that may not be significantly representative of a TBI population with severe multiple injuries. Some patient data about pre-injury drug use and more comorbidities were incomplete. In addition, the effects of different parts of multiple injuries on TBI may be different. Finally, the prognosis was assessed with a short-term outcome. Therefore, further randomized studies based on large populations and appropriate follow-up times are needed to provide stronger evidence for predicting patient outcomes.

\section{Conclusion}

We further confirmed that age, admission GCS score, pupillary reflex, tracheotomy, and platelets count can be used as independent predictors of clinical prognosis in patients with severe TBI with extracranial trauma.

\section{Abbreviations}

sTBI: severe traumatic brain injury; CI: confidence interval; ORs: odds ratios; SD: standard deviation; GCS: Glasgow Coma Scale; GOSE:
Glasgow Outcome Scale Extended; ISS: Injury Severity Score; AIS: abbreviated injury scale; LEVT: lower extremity venous thrombosis; WBC: white blood cell; NLR: neutrophil lymphocyte ratio; BUN: blood urea nitrogen; UA: uric acid; PT: prothrombin time; APTT: activated partial thromboplastin time; INR: International Normalized Ratio; TT: thrombin time.

\section{Acknowledgements}

We would like to express our sincere gratitude to Yongwei Yu, Manli Tang in Tongji Hospital for their work in collecting the clinical data. This work was supported by grants from the National Natural Science Foundation of China (No's. 81801174 to W.W., 81571891 to Z.F.L.). All procedures performed in this study followed the ethical standards of the Tongji Hospital.

\section{Funding}

This work was supported by grants from the National Natural Science Foundation of China (No. 81801174 to W.W. and No. 81571891 to Z.F.L.).

\section{Data availability}

The data for this study are available upon reasonable request to the corresponding authors.

\section{Authors' contributions}

LL designed the study, conducted data analysis, and prepared the manuscript. XS and XJ conducted data collection. LTY and LH checked and analyzed the data. WW and LF reviewed and revised the manuscript.

\section{Competing Interests}

The authors have declared that no competing interest exists.

\section{References}

1. Gritti P, Zangari R, Carobbio A, et al. Acute and Subacute Outcome Predictors in Moderate and Severe Traumatic Brain Injury: A Retrospective Monocentric Study. World Neurosurg. 2019;128:e531-531e540.

2. Brazinova A, Rehorcikova V, Taylor MS, et al. Epidemiology of Traumatic Brain Injury in Europe: A Living Systematic Review. J Neurotrauma. 2018.

3. Tian R, Liu W, Dong J, et al. Prognostic Predictors of Early Outcomes and Discharge Status of Patients Undergoing Decompressive Craniectomy After Severe Traumatic Brain Injury. World Neurosurg. 2019;126:e101-101e108.

4. Khalili H, Paydar S, Safari R, Arasteh P, Niakan A, Abolhasani Foroughi A. Experience with Traumatic Brain Injury: Is Early Tracheostomy Associated with Better Prognosis. World Neurosurg. 2017;103:88-93.

5. Lenell S, Nyholm L, Lewén A, Enblad P. Clinical outcome and prognostic factors in elderly traumatic brain injury patients receiving neurointensive care. Acta Neurochir (Wien). 2019;161(6):1243-1254.

6. Kelly ML, Shammassian B, Roach MJ, Thomas C, Wagner AK. Craniectomy and Craniotomy in Traumatic Brain Injury: A Propensity-Matched Analysis of Long-Term Functional and Quality of Life Outcomes. World Neurosurg. 2018;118:e974-974e981.

7. Nakae R, Takayama Y, Kuwamoto K, Naoe Y, Sato H, Yokota H. Time Course of Coagulation and Fibrinolytic Parameters in Patients with Traumatic Brain Injury. J Neurotrauma. 2016;33(7):688-695.

8. Chen J, Qu X, Li Z, Zhang D, Hou L. Peak Neutrophil-to-Lymphocyte Ratio Correlates with Clinical Outcomes in Patients with Severe Traumatic Brain Injury. Neurocrit Care. 2019;30(2):334-339. 
9. $\mathrm{Li} \mathrm{Z}, \mathrm{Wu} \mathrm{X}, \mathrm{Wu} \mathrm{X}$, et al. Admission circulating monocytes level is an independent predictor of outcome in traumatic brain injury. Brain Inj. 2018;32(4):515-522.

10. Dolmans R, Hulsbergen A, Gormley WB, Broekman M. Routine Blood Tests for Severe Traumatic Brain Injury: Can They Predict Outcomes. World Neurosurg. 2020;136:e60-60e67.

11. Banoei MM, Casault C, Metwaly SM, Winston BW. Metabolomics and Biomarker Discovery in Traumatic Brain Injury. J Neurotrauma. 2018;35(16):1831-1848.

12. Liu H, He J, Zhong J, et al. Clinical and Basic Evaluation of the Prognostic Value of Uric Acid in Traumatic Brain Injury. Int J Med Sci. 2018;15(10):1072-1082.

13. Dong $X Q, Y u W H, D u$, et al. Serum periostin concentrations and outcomes after severe traumatic brain injury. Clin Chim Acta. 2017;471:298-303.

14. Luo LF, Weng JF, Cen M, et al. Prognostic significance of serum translocator protein in patients with traumatic brain injury. Clin Chim Acta. 2019;488:25-30.

15. Polat Ö, Uçkun ÖM, Tuncer C, Belen AD. Is IL-8 level an indicator of clinical and radiological status of traumatic brain injury. Ulus Travma Acil Cerrahi Derg. 2019;25(2):193-197.

16. Tang B, Zhong Z, Qiu Z, et al. Serum soluble TWEAK levels in severe traumatic brain injury and its prognostic significance. Clin Chim Acta. 2019;495:227-232.

17. Zhang ZY, Li J, Ye Q, et al. Usefulness of serum interleukin-33 as a prognostic marker of severe traumatic brain injury. Clin Chim Acta. 2019;497:6-12.

18. Rubenstein R, Chang B, Yue JK, et al. Comparing Plasma Phospho Tau, Total Tau, and Phospho Tau-Total Tau Ratio as Acute and Chronic Traumatic Brain Injury Biomarkers. JAMA Neurol. 2017;74(9):1063-1072

19. Vos PE, Jacobs B, Andriessen TM, et al. GFAP and S100B are biomarkers of traumatic brain injury: an observational cohort study. Neurology. 2010;75(20):1786-1793.

20. Zhang ZL, Huang QB, Zhang Y, Shi P, Sang XG. [Clinical efficacy of damage control orthopaedics in treatment of patients with severe traumatic brain injury combined with limb fracture]. Zhonghua $\mathrm{Yi}$ Xue Za Zhi. 2019;99(48):3797-3802

21. Montazer SH, Jahanian F, Khatir IG, et al. Prognostic Value of Cardiac Troponin I and T on Admission in Mortality of Multiple Trauma Patients Admitted to the Emergency Department: a Prospective Follow-up Study. Med Arch. 2019;73(1):11-14

22. Chelly H, Bahloul M, Ammar R, et al. Clinical characteristics and prognosis of traumatic head injury following road traffic accidents admitted in ICU "analysis of 694 cases". Eur J Trauma Emerg Surg. 2019;45(2):245-253.

23. Rupprecht $\mathrm{H}$, Heppner HJ, Wohlfart K, Türkoglu A. The geriatric polytrauma: Risk profile and prognostic factors. Ulus Travma Acil Cerrahi Derg. 2017;23(2):156-162.

24. Lubelski D, Tharin S, Como JJ, Steinmetz MP, Vallier H, Moore T. Surgical timing for cervical and upper thoracic injuries in patients with polytrauma. J Neurosurg Spine. 2017;27(6):633-637.

25. Tan AL, Chiong Y, Nadkarni N, Cheng J, Chiu MT, Wong TH. Predictors of Change in Functional Outcome at six months and twelve months after Severe Injury: A Retrospective Cohort Study. World J Emerg Surg. 2018;13:57.

26. Watanabe T, Kawai Y, Iwamura A, Maegawa N, Fukushima H, Okuchi K. Outcomes after Traumatic Brain Injury with Concomitant Severe Extracranial Injuries. Neurol Med Chir (Tokyo). 2018;58(9):393-399.

27. Loftis KL, Price J, Gillich PJ. Evolution of the Abbreviated Injury Scale: 1990-2015. Traffic Inj Prev. 2018;19(sup2):S109-109S113.

28. El-Menyar A, Asim M, Latifi R, Bangdiwala SI, Al-Thani H. Predictive value of positive high-sensitivity troponin $\mathrm{T}$ in intubated traumatic brain injury patients. J Neurosurg. 2018;129(6):1541-1549.

29. Baker SP, O'Neill B, Haddon W Jr, Long WB. The injury severity score: a method for describing patients with multiple injuries and evaluating emergency care. J Trauma. 1974;14(3):187-196.

30. Boyd CR, Tolson MA, Copes WS. Evaluating trauma care: the TRISS method. Trauma Score and the Injury Severity Score. J Trauma. 1987;27(4):370-378.

31. Wilson JT, Pettigrew LE, Teasdale GM. Structured interviews for the Glasgow Outcome Scale and the extended Glasgow Outcome Scale: guidelines for their use. J Neurotrauma. 1998;15(8):573-585.

32. Erlebach R, Pagnamenta A, Klinzing S, et al. Age-related outcome of patients after traumatic brain injury: a single-center observation. Minerva Anestesiol. 2017;83(11):1169-1177

33. Dhandapani S, Manju D, Sharma B, Mahapatra A. Prognostic significance of age in traumatic brain injury. J Neurosci Rural Pract. 2012;3(2):131-135.

34. Peck KA, Calvo RY, Schechter MS, et al. The impact of preinjury anticoagulants and prescription antiplatelet agents on outcomes in older patients with traumatic brain injury. J Trauma Acute Care Surg. 2014;76(2):431-436.

35. Grandhi R, Harrison G, Voronovich Z, et al. Preinjury warfarin, but not antiplatelet medications, increases mortality in elderly traumatic brain injury patients. J Trauma Acute Care Surg. 2015;78(3):614-621.

36. Baum J, Entezami P, Shah K, Medhkour A. Predictors of Outcomes in Traumatic Brain Injury. World Neurosurg. 2016;90:525-529.

37. Huang JF, Tsai YC, Rau CS, et al. Systolic blood pressure lower than the heart rate indicates a poor outcome in patients with severe isolated traumatic brain injury: A cross-sectional study. Int J Surg. 2019;61:48-52.
38. Gao L Smielewski P, Czosnyka M, Ercole A. Early Asymmetric Cardio-Cerebral Causality and Outcome after Severe Traumatic Brain Injury. J Neurotrauma. 2017;34(19):2743-2752.

39. Lu Q, Xie Y, Qi X, Li X, Yang S, Wang Y. Is Early Tracheostomy Better for Severe Traumatic Brain Injury? A Meta-Analysis. World Neurosurg. 2018;112:e324-324e330.

40. Humble SS, Wilson LD, McKenna JW, et al. Tracheostomy risk factors and outcomes after severe traumatic brain injury. Brain Inj. 2016;30(13-14):1642-1647.

41. Baron DM, Hochrieser H, Metnitz PG, Mauritz W. Tracheostomy is associated with decreased hospital mortality after moderate or severe isolated traumatic brain injury. Wien Klin Wochenschr. 2016;128(11-12):397-403.

42. Shibahashi K, Sugiyama K, Houda H, Takasu Y, Hamabe Y, Morita A. The effect of tracheostomy performed within $72 \mathrm{~h}$ after traumatic brain injury. $\mathrm{Br} \mathrm{J}$ Neurosurg. 2017;31(5):564-568.

43. Dunham CM, Cutrona AF, Gruber BS, Calderon JE, Ransom KJ, Flowers LL. Early tracheostomy in severe traumatic brain injury: evidence for decreased mechanical ventilation and increased hospital mortality. Int J Burns Trauma. 2014;4(1):14-24.

44. McCully SP, Schreiber MA. Traumatic brain injury and its effect on coagulopathy. Semin Thromb Hemost. 2013;39(8):896-901.

45. Lustenberger $\mathrm{T}$, Talving $\mathrm{P}$, Kobayashi L, et al. Time course of coagulopathy in isolated severe traumatic brain injury. Injury. 2010;41(9):924-928.

46. Zhang B, Gu J, Qiu Y, et al. Level of Platelet Distribution Width and Outcome Prediction in Patients with Traumatic Brain Injury. Clin Lab. 2017;63(10):1711-1715.

47. Furay E, Daley M, Teixeira PG, et al. Goal-directed platelet transfusions correct platelet dysfunction and may improve survival in patients with severe traumatic brain injury. J Trauma Acute Care Surg. 2018;85(5):881-887.

48. Joseph B, Aziz H, Zangbar B, et al. Acquired coagulopathy of traumatic brain injury defined by routine laboratory tests: which laboratory values matter. J Trauma Acute Care Surg. 2014;76(1):121-125.

49. Van Beek JG, Mushkudiani NA, Steyerberg EW, et al. Prognostic value of admission laboratory parameters in traumatic brain injury: results from the IMPACT study. J Neurotrauma. 2007;24(2):315-328

50. Sillesen M, Johansson PI, Rasmussen LS, et al. Fresh frozen plasma resuscitation attenuates platelet dysfunction compared with normal saline in a large animal model of multisystem trauma. J Trauma Acute Care Surg. 2014;76(4):998-1007.

51. Yuan $\mathrm{Q}, \mathrm{Yu} \mathrm{J}, \mathrm{Wu} \mathrm{X}$, et al. Prognostic value of coagulation tests for in-hospital mortality in patients with traumatic brain injury. Scand J Trauma Resusc Emerg Med. 2018;26(1):3

52. MacLeod JB, Lynn M, McKenney MG, Cohn SM, Murtha M. Early coagulopathy predicts mortality in trauma. J Trauma. 2003;55(1):39-44

53. Needham EJ, Helmy A, Zanier ER, Jones JL, Coles AJ, Menon DK. The immunological response to traumatic brain injury. J Neuroimmunol. 2019;332:112-125.

54. Pillay J, Hietbrink F, Koenderman L, Leenen LP. The systemic inflammatory response induced by trauma is reflected by multiple phenotypes of blood neutrophils. Injury. 2007;38(12):1365-1372

55. Makinde HM, Cuda CM, Just TB, Perlman HR, Schwulst SJ. Nonclassical Monocytes Mediate Secondary Injury, Neurocognitive Outcome, and Neutrophil Infiltration after Traumatic Brain Injury. J Immunol. 2017;199(10):3583-3591.

56. Grzalja N, Cicvaric T, Knezevic D, et al. Frequency and perforin expression of different lymphocyte subpopulations in patients with lower limb fracture and thoracic injury. Injury. 2017;48 Suppl 5:S1-1S7.

57. Jo YG, Choi HJ, Kim JC, et al. Deficiencies of Circulating Mucosal-associated Invariant T Cells and Natural Killer T Cells in Patients with Multiple Trauma. J Korean Med Sci. 2017;32(5):750-756

58. Liu YW, Li S, Dai SS. Neutrophils in traumatic brain injury (TBI): friend or foe. J Neuroinflammation. 2018:15(1):146.

59. von Leden RE, Parker KN, Bates AA, Noble-Haeusslein LJ, Donovan MH. The emerging role of neutrophils as modifiers of recovery after traumatic injury to the developing brain. Exp Neurol. 2019;317:144-154.

60. Svedung Wettervik T, Howells T, Ronne-Engström E, et al. High Arterial Glucose is Associated with Poor Pressure Autoregulation, High Cerebral Lactate/Pyruvate Ratio and Poor Outcome Following Traumatic Brain Injury. Neurocrit Care. 2019;31(3):526-533.

61. Zhu C, Chen J, Pan J, Qiu Z, Xu T. Therapeutic effect of intensive glycemic control therapy in patients with traumatic brain injury: A systematic review and meta-analysis of randomized controlled trials. Medicine (Baltimore). 2018;97(30):e11671.

62. Wolahan SM, Prins ML, McArthur DL, et al. Influence of Glycemic Control on Endogenous Circulating Ketone Concentrations in Adults Following Traumatic Brain Injury. Neurocrit Care. 2017;26(2):239-246.

63. Vedantam A, Robertson CS, Gopinath SP. Morbidity and mortality associated with hypernatremia in patients with severe traumatic brain injury. Neurosurg Focus. 2017;43(5):E2.

64. Pin-On P, Saringkarinkul A, Punjasawadwong Y, Kacha S, Wilairat D. Serum electrolyte imbalance and prognostic factors of postoperative death in adult traumatic brain injury patients: A prospective cohort study. Medicine (Baltimore) . 2018;97(45):e13081.

65. de Oliveira DV, Amorim RL, de Cássia Almeida Vieira R, Paiva WS. Traumatic brain injury and hyperglycemia. Oncotarget. 2017;8(12):18622 
66. Vespa P, McArthur DL, Stein N, et al. Tight glycemic control increases metabolic distress in traumatic brain injury: a randomized controlled within-subjects trial. Crit Care Med. 2012;40(6):1923-1929.

67. Green DM, O'Phelan KH, Bassin SL, Chang CW, Stern TS, Asai SM. Intensive versus conventional insulin therapy in critically ill neurologic patients. Neurocrit Care. 2010;13(3):299-306.

68. Litofsky NS, Martin S, Diaz J, et al. The Negative Impact of Anemia in Outcome from Traumatic Brain Injury. World Neurosurg. 2016;90:82-90.

69. Travers S, Martin S, Litofsky NS. The effects of anaemia and transfusion on patients with traumatic brain injury: A review. Brain Inj. 2016;30(13-14):1525-1532.

70. Loftus TJ, Mira JC, Miller ES, et al. The Postinjury Inflammatory State and the Bone Marrow Response to Anemia. Am J Respir Crit Care Med. 2018;198(5):629-638. 